\title{
Fabrication and mechanical properties of high-dispersion-treated carbon nanofiber/alumina composites
}

\author{
Naoki UEDA, Tomohiko YAMAKAMI, Tomohiro YAMAGUCHI, Kunio KITAJIMA, \\ Yuki USUI, ${ }^{*}$ Kaoru AOKI, ${ }^{*}$ Takefumi NAKANISHI, ${ }^{* *}$ Fumiaki MIYAJI, ${ }^{* *}$ \\ Morinobu ENDO, Naoto SAITO ${ }^{* * *}$ and Seiichi TARUTA ${ }^{\dagger}$ \\ Faculty of Engineering, Shinshu University, 4-17-1 Wakasato, Nagano, Nagano 380-8553 \\ *Shinshu University School of Medicine, 3-1-1 Asahi, Matsumoto, Nagano 390-8621 \\ ${ }^{* *}$ Japan Medical Materials Corporation, 3-3-31 Miyahara, Yodogawa-ku, Osaka 532-0003 \\ *** Department of Applied Physical Therapy, Shinshu University School of Health Sciences, \\ 3-1-1 Asahi, Matsumoto, Nagano 390-8621
}

\begin{abstract}
High-dispersion-treated carbon nanofibers (CNFs) were used to fabricate uniformly-dispersed CNFs-alumina composites with enhanced mechanical properties. The treatment was effective in obtaining dense and uniform composites. The composites containing 0.4-0.8 wt \% CNFs were densified to a relative density of more than $99 \%$ by vacuum sintering and subsequent hot isostatic pressing, and those containing 1.6-2.5 wt \% CNFs were densified to full density by plasma activated sintering. The maximum bending strength of the composites $(1050 \mathrm{MPa})$ was approximately the same as the bending strength of monolithic alumina (1079 MPa). The maximum fracture toughness of the composites was $5.9 \mathrm{MPa} \cdot \mathrm{m}^{0.5}$, which was a $69 \%$ increase compared with the fracture toughness of monolithic alumina $\left(3.5 \mathrm{MPa} \cdot \mathrm{m}^{0.5}\right)$. Fracture toughness $\left(\mathrm{K}_{\mathrm{IC}}\right)$ increased rapidly with a decrease in alumina grain size $(G)$, and we found that the relationship could be expressed by the following equation: $K_{I C}=\left(k_{1} / G^{2}\right)+k_{2}$ (where $k_{1}$ and $k_{2}$ are constants).
\end{abstract}

(C)2010 The Ceramic Society of Japan. All rights reserved.

Key-words : Carbon nanotube, Alumina, Composites, Sintering, Microstructure development, Mechanical properties

[Received May 11, 2010; Accepted June 17, 2010]

\section{Introduction}

It is well-known that alumina ceramics are typical ceramics and have superior properties, such as high mechanical strength, excellent hardness, high heat resistance, excellent chemical durability, and low electrical conductivity. Thus, alumina ceramics have been widely applied in various fields as engineering materials, electrical insulators, biomaterials, optical materials, and so forth. ${ }^{1)-3)}$ However, their brittleness is the major problem in terms of structural use, and limits their application fields. ${ }^{4-13)}$

Carbon nanotubes (CNTs) were first reported by Oberlin et al. in $1976 .{ }^{14)}$ Then, a report in 1991 by Iijima ${ }^{15)}$ triggered huge worldwide interest in CNTs as incredible nanomaterials. CNTs have extraordinary tensile strength and elastic stiffness. ${ }^{16)-21)}$ Due to such superior mechanical properties and the high aspect ratio, it seems that CNTs are the best reinforcement fibers to improve the brittleness of ceramics.

However, some reports on CNTs/ceramic composites $^{9), 11), 13), 22)-27)}$ have shown that CNTs provided no or only little improvement in mechanical properties of the composites, such as strength and fracture toughness, because they were not uniformly-dispersed in the ceramic matrix. CNTs are essentially hydrophobic materials, and, furthermore, they tend to agglomerate because of the high van der Waals interaction force. The agglomeration of CNTs acts as a defect in the composites and causes a degradation of the mechanical properties of the composites. Therefore, the uniform dispersion of CNTs in the

\footnotetext{
Corresponding author: S. Taruta; E-mail: staruta@shinshu-u.ac.jp
}

ceramic matrix is indispensable for the fabrication of CNTs/ ceramic composites with enhanced mechanical properties. However, this has always been a difficult problem.

On the other hand, there have been some reports on improvements in the mechanical properties of CNTs/alumina composites. ${ }^{4)-8), 10), 12)}$ Zhan et al. reported that single-walled carbon nanotubes (SWCNTs)/alumina composites that were prepared using the ropes of SWCNTs showed a three-fold increase in fracture toughness compared with monolithic alumina. ${ }^{10), 12)}$ Yamamoto et al. reported that acid-treated multi-walled carbon nanotubes (MWCNTs) were dispersed homogeneously in the alumina matrix, and the nanodefects that formed on the surface of the MWCNTs through the acid treatment improved the mechanical properties of the composites by the anchor effect. ${ }^{4)}$ Estili et al. reported that individually alumina-decorated MWCNTs with optimized composition and intimate bonding, which were produced by employing heteroaggregation, resulted in obtaining homogeneously dispersed MWCNTs-alumina matrix nanocomposites, and gave high interfacial compatibility and wetting between MWCNTs and alumina, which led to a $70 \%$ increase in the fracture toughness of the composite. ${ }^{5), 6)}$

In this study, we used high-dispersion-treated carbon nanofibers (CNFs) to fabricate uniformly-dispersed CNFs-alumina composites with enhanced mechanical properties. The composites were prepared either by pressureless sintering in a vacuum with a subsequent hot isostatic pressing (HIP), or by plasma sintering. The densification, microstructure development and mechanical properties of the composites were investigated, and we identified a novel relationship between the fracture toughness and the alumina grain size. 


\section{Experimental procedure}

\subsection{Preparation of the composites}

The CNFs used in this study were vapor-grown carbon fibers (VGCF-S, Showa Denko, Japan), which are a type of MWCNT. The diameter and length of the CNFs were $100 \mathrm{~nm}$ and 10 $20 \mu \mathrm{m}$, respectively. The CNFs were high-dispersion-treated using an ultra fine grinding machine, which is similar to wet jet milling. In this treatment, the CNFs were passed through slit-like channels using high-pressure ethanol fluid (200 MPa) with a small amount of dispersants, and the agglomerations of CNFs were disentangled by applying strong mechanical stresses, such as shear stress, impulsive force, and so forth, which were generated in the channels. In this way, a highly dispersed CNF ethanol solution was prepared, and was mixed with high purity alumina powder (TM-DAR, average particle size $0.1 \mu \mathrm{m}$, Taimei Chemicals, Japan) by ball-milling for $24 \mathrm{~h}$. The dry powder mixtures contained $0.4-2.5 \mathrm{wt} \% \mathrm{CNFs}$. In addition, the pristine CNFs were dispersed in ethanol with a small amount of dispersant using ultrasonic agitation, and then mixed with the high purity alumina powder by ball-milling. The obtained dry powder mixtures were passed through a 100 -mesh sieve.

The powder mixtures containing $0.4-1.6 \mathrm{wt} \% \mathrm{CNFs}$ were compacted by cold isostatic pressing (CIP) at $200 \mathrm{MPa}$, sintered in a vacuum at $1250-1350^{\circ} \mathrm{C}$ for $0.5-2 \mathrm{~h}$, and then treated by hot isostatic pressing (HIP) at $180 \mathrm{MPa}$ in a nitrogen atmosphere. The temperatures and times of HIP were the same as those for the vacuum sintering. In addition, the powder mixtures containing 1.6 and $2.5 \mathrm{wt} \%$ CNFs were consolidated by plasma activated sintering (PAS). The powder mixture containing $1.6 \mathrm{wt} \% \mathrm{CNFs}$ was sintered at $1375^{\circ} \mathrm{C}$ for $80 \mathrm{~s}$ with a uniaxial pressure of $40 \mathrm{MPa}$ in a vacuum, and that containing $2.5 \mathrm{wt} \% \mathrm{CNFs}$ was sintered at $1350^{\circ} \mathrm{C}$ for $1-15 \mathrm{~min}$ with $50 \mathrm{MPa}$ in a vacuum. The heating rate of PAS was $300^{\circ} \mathrm{C} / \mathrm{min}$.

Monolithic alumina ceramic, which was the control specimen in this study, was prepared using the high purity alumina powder. The alumina powder was compacted by CIP, sintered at $1300^{\circ} \mathrm{C}$ for $2 \mathrm{~h}$ in air, and then treated by HIP at $1300^{\circ} \mathrm{C}$ and $180 \mathrm{MPa}$ for $2 \mathrm{~h}$ in a nitrogen atmosphere.

\subsection{Estimation of the composites}

The bulk densities of the composites were measured using the Archimedes method. The relative densities were calculated using the bulk densities of the composites and theoretical densities of alumina $\left(3.987 \mathrm{~g} / \mathrm{cm}^{3}\right)$ and VGCF-S $\left(2.0 \mathrm{~g} / \mathrm{cm}^{3}\right)$. Their microstructures were observed using a scanning electron microscopy (SEM) and a transmission electron microscopy (TEM).

The fracture toughness was measured using the Vickers indentation fracture method. The composites were finally polished to a mirror finish using diamond slurry with a particle size of $1 \mu \mathrm{m}$, and then a $196.1 \mathrm{~N}$ load was applied on the polished surface for $10 \mathrm{~s}$. The lengths of the impression diagonals $2 a$ and the surface radial cracks $2 c$ were measured immediately after the indentation, and the crack-to-indent ratios $(c / a)$ were larger than $2.5^{28)-30)}$ in every indentation. So the fracture toughness was calculated by the following formula:

$$
\mathrm{K}_{\mathrm{IC}}=A\left(\frac{E}{H}\right)^{n} \cdot \frac{P}{c^{3 / 2}}
$$

where $A$ and $n$ are dimensionless constants, $E$ is the Young's modulus, $H$ is the Vickers hardness, $P$ is the applied indentation load, and $c$ is the half-length of the surface radial crack. The constants $A=0.018$ and $n=0.5$, which were reported by Miyoshi et al. ${ }^{31)}$ were used to calculate the fracture toughness in this study. The mechanical strength of the composites with $3 \mathrm{~mm} \times$ $2 \mathrm{~mm} \times 15 \mathrm{~mm}$ was measured by a three-point bending test, with a crosshead speed of $0.5 \mathrm{~mm} / \mathrm{min}$ and a span length of $6 \mathrm{~mm}$. For the specimens sintered by PAS, the load in the three-point test was applied in the same direction in which the pressure was applied during PAS. The alumina grain sizes of the composites, which were polished and thermally etched at temperatures 50 $150^{\circ} \mathrm{C}$ lower than the sintering temperatures for $1 \mathrm{~h}$, were measured using the line-intercept method on the SEM photographs. The measured individual grain size was the maximum length of the grain in the specified direction. The average alumina grain size was determined from the sizes of about 200 grains.

\section{Results and discussion}

\subsection{High-dispersion-treated CNFs}

SEM images of pristine and high-dispersion-treated CNFs are shown in Fig. 1. The pristine CNFs became tangled with one another and formed some large agglomerations. However, they were disentangled using high-dispersion treatment, and large agglomerations were not observed.

The Raman spectra of the pristine and the high-dispersiontreated CNFs were analyzed. The results showed that the intensity ratio of the D-band (defect-mode) at $1350 \mathrm{~cm}^{-1}$ to the G-band $\left(E_{2 \mathrm{~g} 2}\right.$ mode) at $1582 \mathrm{~cm}^{-1}$ of the CNFs had not been changed by the high-dispersion treatment. In addition, after the pristine CNFs were ball-milled for $24 \mathrm{~h}$ using an alumina-pot and alumina beads, the Raman spectra of the CNFs were measured. The intensity ratio of the D-band to the G-band of the CNFs was also not altered by the ball-milling. Such results indicate that the structural defects of the CNFs were not increased by the highdispersion treatment or by the ball-milling.

\subsection{Sintering behavior of the composites}

The relative densities of the $0.8 \mathrm{wt} \% \mathrm{CNFs} /$ alumina composites sintered in a vacuum are shown in Fig. 2. The high-
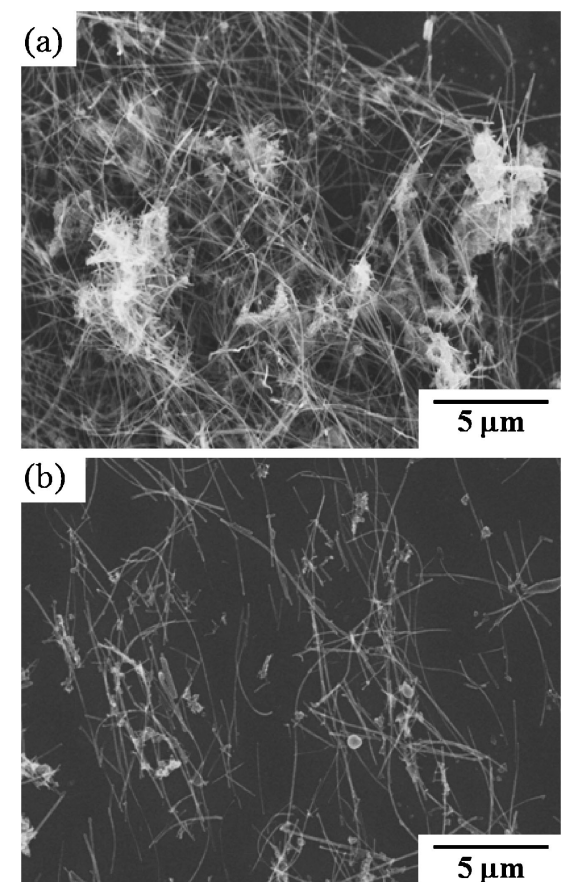

Fig. 1. SEM images of (a) pristine CNFs and (b) high-dispersiontreated CNFs. 
dispersion-treated CNFs/alumina composite sintered in a vacuum at $1250-1350^{\circ} \mathrm{C}$ had relative densities of $97.6-98.3 \%$, while the pristine CNFs/alumina composite were only 90.9-96.8\%. The difference between the relative densities of both composites was larger at lower temperatures, especially at $1250^{\circ} \mathrm{C}$. The SEM images of the fractured surfaces of the $0.8 \mathrm{wt} \% \mathrm{CNFs} /$ alumina composites sintered in a vacuum at $1350^{\circ} \mathrm{C}$ for $2 \mathrm{~h}$ are shown in Fig. 3. While the pristine CNFs were clustered in some areas of the composite (Fig. 3(a)), the high-dispersion-treated CNFs were dispersed more uniformly in the alumina matrix (Fig. 3(b)). The high-dispersion-treated CNFs/alumina composite sintered in a vacuum at $1250-1350^{\circ} \mathrm{C}$ was densified to the relative densities of more than $99 \%$ by HIP treatment. It is obvious from above results that using high-dispersion-treated CNFs was effective in obtaining dense and uniform composites. Therefore, in the following study, only the high-dispersion-treated CNFs were used and are represented simply as "CNFs".

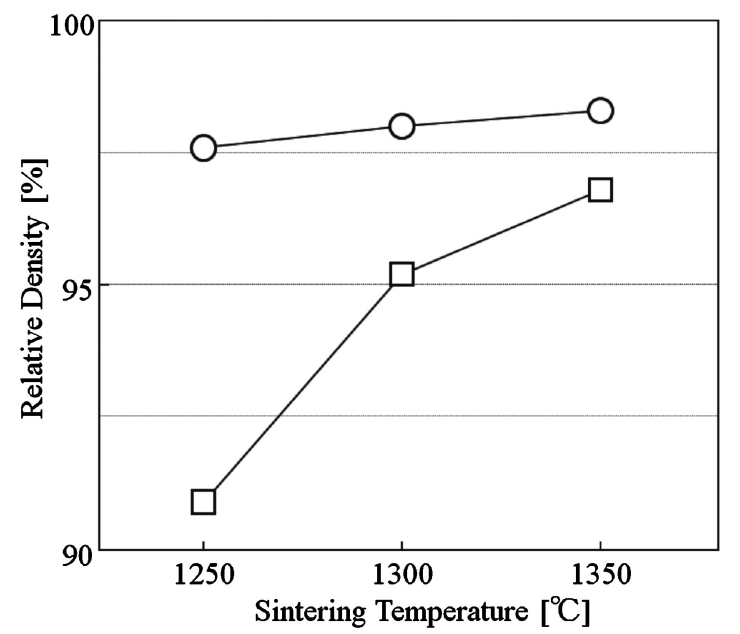

Fig. 2. Relative densities of $(\square) 0.8 \mathrm{wt} \%$ pristine CNFs/alumina and (○) $0.8 \mathrm{wt} \%$ high-dispersion-treated $\mathrm{CNFs} /$ alumina composites.
The 0.4 and 0.8 wt $\%$ CNFs/alumina composites were densified to relative densities of $99.0-99.6 \%$ by sintering in a vacuum and subsequent HIP treatment. However, the highest relative density of the $1.6 \mathrm{wt} \% \mathrm{CNFs} /$ alumina composite was only 96.7\%. In the $1.6 \mathrm{wt} \% \mathrm{CNFs/alumina}$ composite, there were no agglomerations of CNFs but some areas where the CNFs were clustered were observed (Fig. 4(b)). The CNFs generally inhibited densification among the alumina grains, particularly the clusters of CNFs did not cause the composite to densify to a very high degree. In the fabrication of the CNFs/alumina
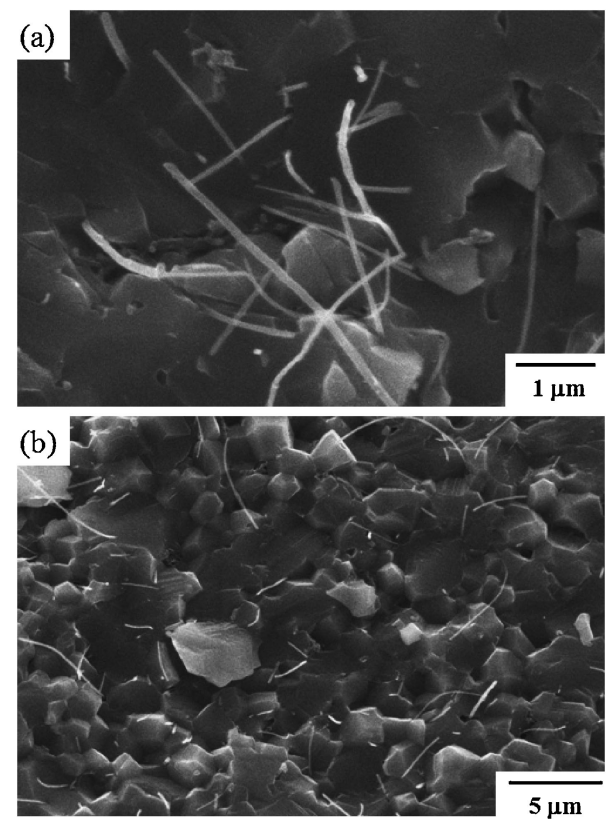

Fig. 3. SEM images of fractured surfaces of (a) $0.8 \mathrm{wt} \%$ pristine $\mathrm{CNFs} /$ alumina and (b) $0.8 \mathrm{wt} \%$ high-dispersion-treated $\mathrm{CNFs} /$ alumina composites sintered in a vacuum at $1350^{\circ} \mathrm{C}$ for $2 \mathrm{~h}$.
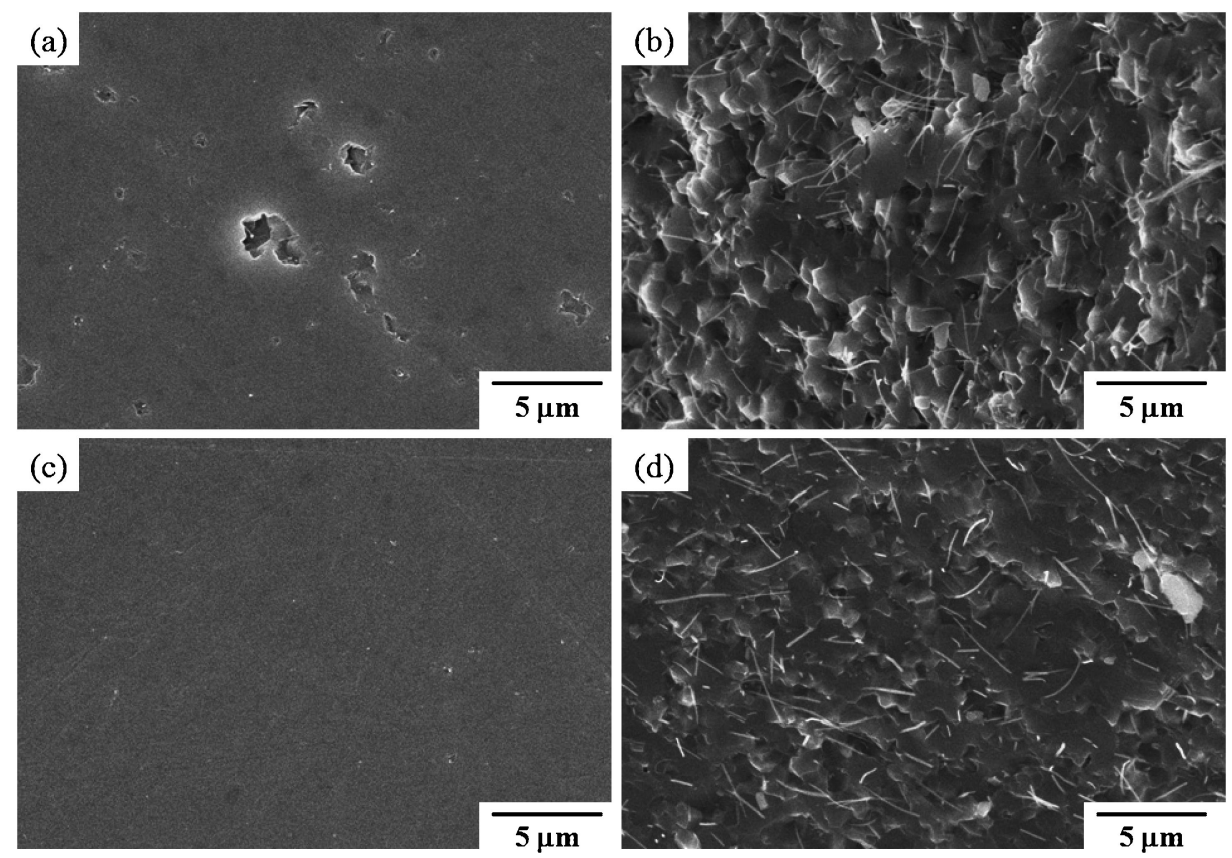

Fig. 4. SEM images of (a) polished and (b) fractured surfaces of $1.6 \mathrm{wt} \% \mathrm{CNFs} /$ alumina composite sintered in a vacuum and then treated by $\mathrm{HIP}$ at $1350^{\circ} \mathrm{C}$ for $2 \mathrm{~h}$; and (c) polished and (d) fractured surfaces of $1.6 \mathrm{wt} \% \mathrm{CNFs} /$ alumina composite sintered by PAS at $1375^{\circ} \mathrm{C}$ for $80 \mathrm{~s}$. 
Table 1. Relative density, mechanical properties, and average alumina grain size of the CNFs/alumina composites

\begin{tabular}{|c|c|c|c|c|c|c|c|c|}
\hline $\begin{array}{c}\text { CNT } \\
\text { content } \\
{[\mathrm{wt} \%]}\end{array}$ & $\begin{array}{l}\text { Sintering } \\
\text { method }\end{array}$ & $\begin{array}{l}\text { Sintering } \\
\text { Temp. } \\
\text { and time }\end{array}$ & $\begin{array}{c}\text { Relative } \\
\text { density } \\
{[\%]}\end{array}$ & $\begin{array}{l}\text { Young's } \\
\text { modulus } \\
{[\mathrm{GPa}]}\end{array}$ & $\begin{array}{c}\text { Vickers } \\
\text { hardness } \\
{[\mathrm{GPa}]}\end{array}$ & $\begin{array}{c}\text { Fracture } \\
\text { toughness } \\
{\left[\mathrm{MPa} \cdot \mathrm{m}^{0.5}\right]}\end{array}$ & $\begin{array}{c}\text { Bending } \\
\text { strength } \\
{[\mathrm{MPa}]}\end{array}$ & $\begin{array}{c}\text { Ave. alumina } \\
\text { grain size } \\
{[\mu \mathrm{m}]}\end{array}$ \\
\hline 0 & $\begin{array}{l}\text { PLA }^{*} \\
+ \text { HIP }\end{array}$ & $\begin{array}{c}1300^{\circ} \mathrm{C} \\
2 \mathrm{~h}\end{array}$ & 99.6 & 382 & $21.3 \pm 0.3$ & $3.5 \pm 0.1$ & $1079 \pm 69$ & $1.23 \pm 0.5$ \\
\hline 0.4 & $\begin{array}{l}\text { PLV }^{* *} \\
+ \text { HIP }\end{array}$ & $\begin{array}{c}1350^{\circ} \mathrm{C} \\
2 \mathrm{~h}\end{array}$ & 99.2 & 384 & $19.9 \pm 0.7$ & $3.4 \pm 0.4$ & & $1.97 \pm 0.8$ \\
\hline 0.8 & $\begin{array}{l}\text { PLV } \\
+ \text { HIP }\end{array}$ & $\begin{array}{c}1250^{\circ} \mathrm{C} \\
2 \mathrm{~h}\end{array}$ & 99.0 & 392 & $19.6 \pm 0.6$ & $4.3 \pm 0.4$ & & $0.65 \pm 0.2$ \\
\hline 0.8 & $\begin{array}{l}\text { PLV } \\
+ \text { HIP }\end{array}$ & $\begin{array}{c}1300^{\circ} \mathrm{C} \\
2 \mathrm{~h}\end{array}$ & 99.5 & 380 & $19.9 \pm 0.4$ & $4.0 \pm 0.3$ & $491 \pm 77$ & $0.92 \pm 0.4$ \\
\hline 0.8 & $\begin{array}{l}\text { PLV } \\
+ \text { HIP }\end{array}$ & $\begin{array}{c}1350^{\circ} \mathrm{C} \\
0.5 \mathrm{~h}\end{array}$ & 99.6 & 383 & $20.4 \pm 0.6$ & $4.2 \pm 0.3$ & $578 \pm 81$ & $0.80 \pm 0.4$ \\
\hline 0.8 & $\begin{array}{c}\text { PLV } \\
+ \text { HIP }\end{array}$ & $\begin{array}{c}1350^{\circ} \mathrm{C} \\
2 \mathrm{~h}\end{array}$ & 99.5 & 375 & $19.7 \pm 0.7$ & $3.4 \pm 0.2$ & $672 \pm 109$ & $1.79 \pm 0.6$ \\
\hline 1.6 & PAS & $\begin{array}{c}1375^{\circ} \mathrm{C} \\
80 \mathrm{~s}\end{array}$ & 100 & 342 & $18.5 \pm 1.5$ & $4.2 \pm 0.5$ & $1050 \pm 239$ & $0.67 \pm 0.3$ \\
\hline 2.5 & PAS & $\begin{array}{c}1350^{\circ} \mathrm{C} \\
3 \mathrm{~min}\end{array}$ & 99.8 & 359 & $18.1 \pm 0.5$ & $5.9 \pm 0.5$ & $841 \pm 186$ & $0.53 \pm 0.2$ \\
\hline 2.5 & PAS & $\begin{array}{c}1350^{\circ} \mathrm{C} \\
5 \mathrm{~min}\end{array}$ & 99.7 & 348 & $19.8 \pm 0.5$ & $4.2 \pm 0.4$ & & $0.70 \pm 0.2$ \\
\hline 2.5 & PAS & $\begin{array}{c}1350^{\circ} \mathrm{C} \\
7 \mathrm{~min}\end{array}$ & 99.9 & 349 & $19.0 \pm 0.4$ & $4.5 \pm 0.3$ & & $0.68 \pm 0.3$ \\
\hline 2.5 & PAS & $\begin{array}{c}1350^{\circ} \mathrm{C} \\
10 \mathrm{~min}\end{array}$ & 99.8 & 361 & $19.4 \pm 0.4$ & $4.8 \pm 0.2$ & & $0.63 \pm 0.2$ \\
\hline 2.5 & PAS & $\begin{array}{c}1350^{\circ} \mathrm{C} \\
15 \mathrm{~min}\end{array}$ & 100 & 355 & $18.9 \pm 0.4$ & $4.7 \pm 0.6$ & & $0.66 \pm 0.2$ \\
\hline 2.5 & PAS & $\begin{array}{c}1350^{\circ} \mathrm{C} \\
3 \min ^{* * *}\end{array}$ & 99.7 & 345 & $17.6 \pm 0.5$ & $5.3 \pm 0.3$ & & $0.63 \pm 0.2$ \\
\hline
\end{tabular}

*Pressureless sintering in air

**Pressureless sintering in vacuum

$* * *$ Heating rate $100^{\circ} \mathrm{C} / \mathrm{min}$

composites with relative densities of more than $99 \%$ by sintering in a vacuum and subsequent HIP treatment, there was a critical additive amount of CNFs because clusters of CNFs formed more easily in the composites containing larger amounts of CNFs during sintering. The critical additive amount of CNFs was within the range from 0.8 to $1.6 \mathrm{wt} \%$.

The relative densities of the composites sintered by PAS are shown in Table 1. PAS was effective in making very dense composites containing CNFs of more than $1.6 \mathrm{wt} \%$. The 1.6 and $2.5 \mathrm{wt} \% \mathrm{CNFs} /$ alumina composites sintered by PAS achieved full density. The SEM images of the $1.6 \mathrm{wt} \% \mathrm{CNFs} /$ alumina composite are shown in Fig. 4. There was hardly any pore observed on the polished surface of the composite sintered by PAS (Fig. 4(c)), while some pores with sizes of $<2 \mu \mathrm{m}$ were observed on the polished surface of the composite sintered in a vacuum and then treated by HIP (Fig. 4(a)). Areas where CNFs were clustered were observed not only in the composite sintered in a vacuum followed by HIP treatment (Fig. 4(b)) but also in the composite sintered by PAS (Fig. 4(d)). However, the areas in the composite sintered by PAS consisted of fewer CNFs and were smaller than those in the composite sintered in a vacuum and with subsequent HIP treatment. The areas clustered with CNFs may be formed by the grain growth of alumina even if the CNFs are dispersed uniformly in the green compacts. The rapid heating rate, short sintering time, additional uniaxial pressure, and unique sintering process during PAS promoted the densification of the composites and hindered the grain growth of alumina, which resulted in smaller areas clustered with fewer CNFs in the composites sintered by PAS. Therefore, PAS made possible the fabrication of the 1.6-2.5 wt \% CNFs/alumina composites with full density.

SEM images of the $0.8 \mathrm{wt} \% \mathrm{CNFs} /$ alumina composite are shown in Fig. 5. CNFs bent at intergranulars were observed, as shown by the arrows in Fig. 5. Such bending is one of the unique properties of CNFs, which is due to their flexibility, and from this point of view, CNFs differ from ceramic whiskers and fibers. Most CNFs were distributed at intergranulars in the composite and a few CNFs passed through the inside of the alumina grains. Some CNFs were located in the same sites of the intergranulars, as shown in the circles in Fig. 5. These observations suggest that CNFs dispersed uniformly in the green compacts migrated with the grain boundaries through the grain growth of the alumina. In the composites containing larger amounts of CNFs, more CNFs were gathered in the same sites of the intergranulars by the slight grain growth of alumina, and if the alumina grain growth is allowed to progress much further, the agglomerations consisting of many CNFs will form at the intergranulars.

\subsection{Mechanical properties of the composites}

The mechanical properties of the $0-2.5 \mathrm{wt} \% \mathrm{CNFs} /$ alumina composites are listed in Table 1. The bending strength of the $1.6 \mathrm{wt} \% \mathrm{CNFs} /$ alumina composite sintered by PAS at $1375^{\circ} \mathrm{C}$ for $80 \mathrm{~s}(1050 \mathrm{MPa})$ was approximately the same as that of the monolithic alumina $(1079 \mathrm{MPa})$. However, the other composites showed much lower bending strength than the monolithic alumina. The SEM images of the fractured surfaces of the 

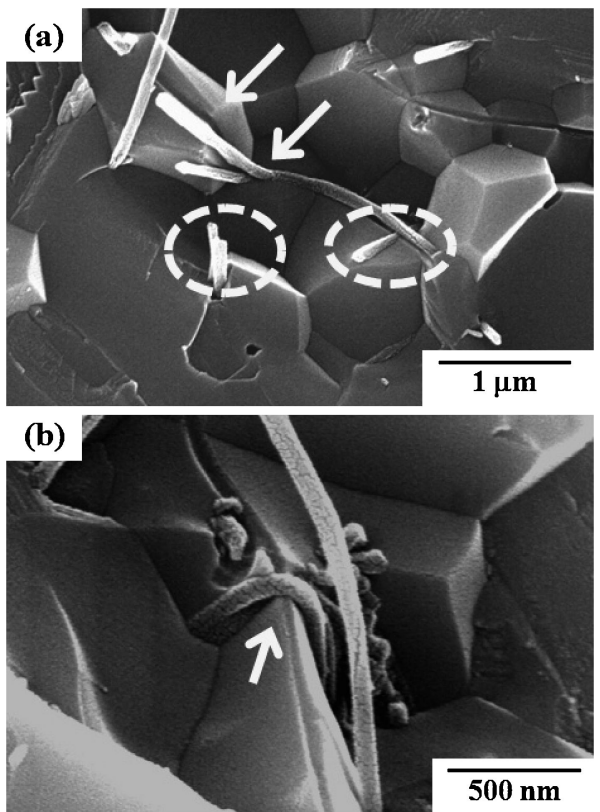

Fig. 5. SEM images of the fracture surface of the $0.8 \mathrm{wt} \% \mathrm{CNFs} /$ alumina composite sintered in a vacuum and then treated by HIP at $1350^{\circ} \mathrm{C}, 0.5 \mathrm{~h}$. (a) A bending $\mathrm{CNF}$ along the intergranulars of alumina grains, and (b) a bent CNF at an intergranular with an acute angle. The arrows indicate the bending of CNFs, and the circles indicate bundles of $\mathrm{CNFs}$ at the intergranulars of alumina grains.
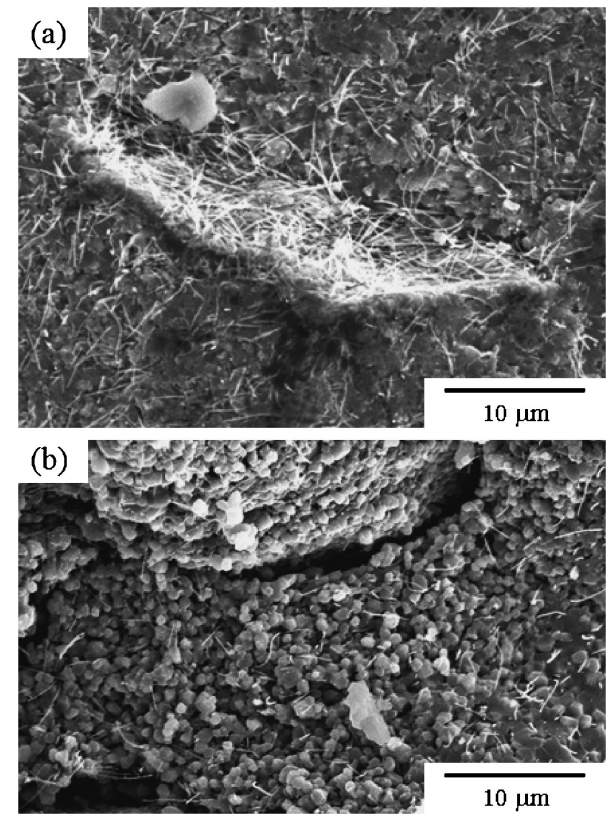

Fig. 6. SEM images of fractured surface of composites used for the measurement of bending strength. (a) $2.5 \mathrm{wt} \% \mathrm{CNFs} /$ alumina composite sintered at $1350^{\circ} \mathrm{C}$ for $3 \mathrm{~min}$ by PAS, and (b) $0.8 \mathrm{wt} \% \mathrm{CNFs} /$ alumina composite sintered at $1250^{\circ} \mathrm{C}$ for $2 \mathrm{~h}$ by vacuum sintering and then treated by HIP.

composites used for the measurement of bending strength are shown in Fig. 6. It seems that the CNFs were dispersed very uniformly in the composites (Fig. 3(b), and Fig. 4(d)), but only a few agglomerations of CNFs existed in the composites, notably in the composite containing $2.5 \mathrm{wt} \% \mathrm{CNFs}$, which showed large agglomerations (Fig. 6(a)). Also, some composites, especially
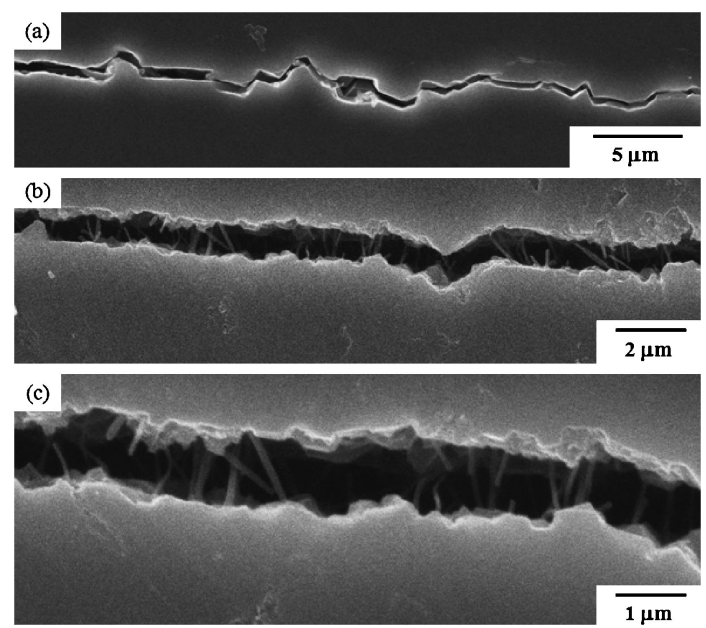

Fig. 7. SEM images of Vickers cracks on the surface of (a) monolithic alumina sintered in air and then treated by $\mathrm{HIP}$ at $1300^{\circ} \mathrm{C}$ for $2 \mathrm{~h}$, and (b) and (c) $2.5 \mathrm{wt} \% \mathrm{CNFs} /$ alumina composite sintered by PAS at $1350^{\circ} \mathrm{C}$ for $7 \mathrm{~min}$.

those sintered at lower temperatures, showed only a few regions that were insufficiently sintered (Fig. 6(b)). These agglomerations and regions acted as fracture origins in the composites, and thus caused a degradation in the bending strength. On the other hand, the maximum bending strength of the five samples of the $1.6 \mathrm{wt} \% \mathrm{CNFs} /$ alumina composite measured was $1314 \mathrm{MPa}$, which was 5\% larger than that of the five samples of the monolithic alumina (1256 MPa). These results suggest that the composites have a potential to show a higher average strength than the monolithic alumina when there are no large agglomerations of CNFs and insufficiently sintered regions in the composites.

The fracture toughness of the 0.4 and $0.8 \mathrm{wt} \% \mathrm{CNFs}$ /alumina composites sintered at $1350^{\circ} \mathrm{C}$ for $2 \mathrm{~h}$ in a vacuum and then treated by HIP were approximately the same as that of the monolithic alumina $\left(3.5 \mathrm{MPa} \cdot \mathrm{m}^{0.5}\right)$. On the other hand, the $0.8 \mathrm{wt} \% \mathrm{CNFs} /$ alumina composite sintered at lower temperatures or for shorter times and the 1.6 and $2.5 \mathrm{wt} \% \mathrm{CNFs} /$ alumina composites sintered by PAS showed a higher fracture toughness of more than $4.0 \mathrm{MPa} \cdot \mathrm{m}^{0.5}$. The fracture toughness of the $2.5 \mathrm{wt} \% \mathrm{CNFs}$ /alumina composite sintered at $1350^{\circ} \mathrm{C}$ for $3 \mathrm{~min}$ by PAS was the maximum $\left(5.9 \mathrm{MPa} \cdot \mathrm{m}^{0.5}\right)$ found in this study, which represented a $69 \%$ increase compared with that of the monolithic alumina.

SEM images of Vickers cracks on the surface of the composite and the monolithic alumina are shown in Fig. 7. Crack deflection was observed for the monolithic alumina ceramic (Fig. 7(a)) but it was not observed for all CNFs/alumina composites (Fig. 7(b)). On the other hand, the bridgings and/or pull-outs of CNFs were observed in the Vickers cracks of the composites (Fig. 7(c)). TEM images of the interface between a $\mathrm{CNF}$ and an alumina grain of the $0.8 \mathrm{wt} \% \mathrm{CNFs} /$ alumina composite are shown in Fig. 8. The nanodefects reported by Yamamoto et al. ${ }^{4)}$ were not observed on the surface of the CNFs. The CNFs adhered closely to the alumina grains and there were no apertures at the interface between the alumina grains and the CNFs. Therefore, the direct factor in the improvement of the fracture toughness was not crack deflection but the bridging and/or pull-out of the CNFs.

The relationship between fracture toughness $\left(\mathrm{K}_{\mathrm{IC}}\right)$ and average alumina grain size $(\mathrm{G})$ of the composites is shown in Fig. 9. 

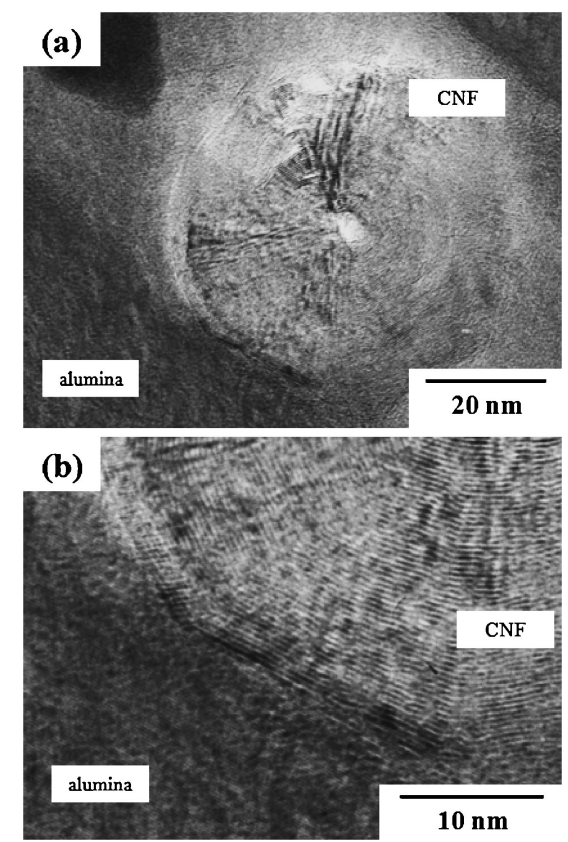

Fig. 8. TEM images of the interface between a CNF and an alumina grain in $0.8 \mathrm{wt} \% \mathrm{CNFs} /$ alumina composite sintered in a vacuum and then treated by HIP at $1350^{\circ} \mathrm{C}$ for $2 \mathrm{~h}$. (a) The cross section of CNF showing a stump-like plane, and (b) the high magnification of the interface between a CNF and an alumina grain.

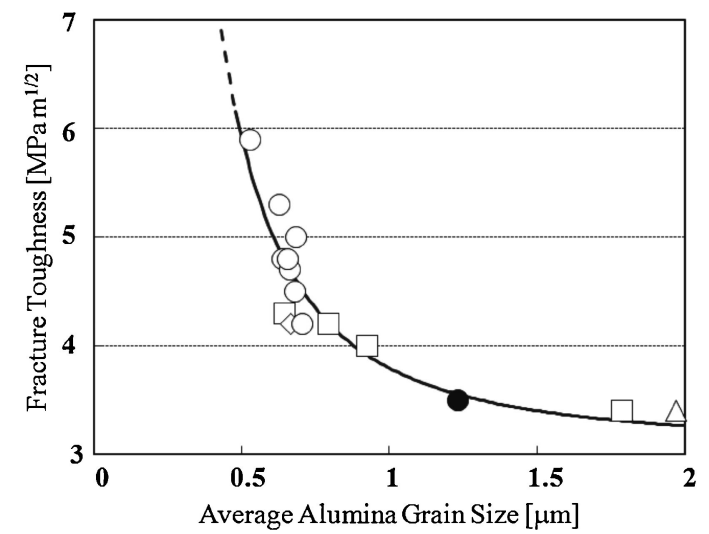

Fig. 9. Relationship between fracture toughness $\left(\mathrm{K}_{\mathrm{IC}}\right)$ and average alumina grain size $(\mathrm{G}) .(\bigcirc) 2.5 \mathrm{wt} \% \mathrm{CNFs} /$ alumina composite, $(\diamond)$ $1.6 \mathrm{wt} \% \mathrm{CNFs} /$ alumina composite, $(\square) 0.8 \mathrm{wt} \% \mathrm{CNFs} /$ alumina composite, $(\triangle) 0.4 \mathrm{wt} \% \mathrm{CNFs} /$ alumina composite, and $(\bigcirc)$ monolithic alumina ceramic.

There are some reports that the fracture toughness of monolithic alumina ceramics was increased with an increase in alumina grain size, ${ }^{32)-35)}$ and also similar toughening effects were observed in SiC-whisker/alumina composites. ${ }^{32)}$ Rice et al. reported that the fracture energy of monolithic alumina ceramics becomes greater with an increase in alumina grain size from about $10 \mu \mathrm{m}$ to $100 \mu \mathrm{m} .^{34)}$ On the other hand, the fracture toughness of the CNFs/alumina composites increased rapidly with a decrease in alumina grain size, and approached a constant value with an increase in alumina grain size. This means that the effect of the bridging and/or pull-out of the CNFs on the fracture toughness became greater with a decrease in alumina grain size, while it disappeared gradually with an increase in alumina grain size.

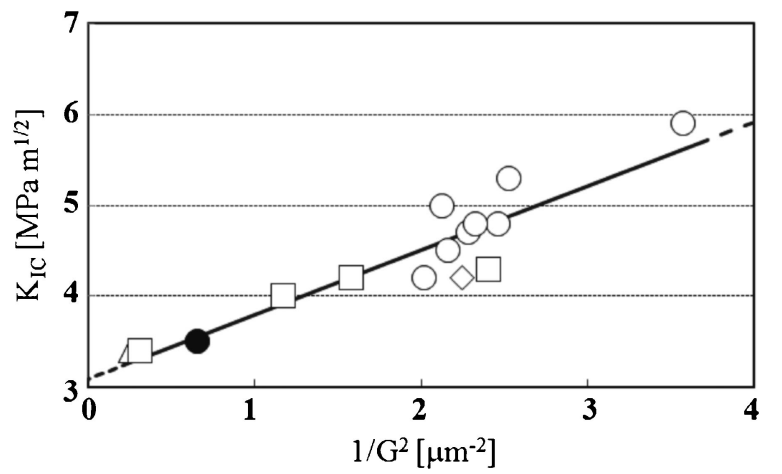

Fig. 10. Relationship between $\mathrm{K}_{\mathrm{IC}}$ and $1 / \mathrm{G}^{2}$. (O) $2.5 \mathrm{wt} \% \mathrm{CNFs} /$ alumina composite, $(\diamond) 1.6 \mathrm{wt} \% \mathrm{CNFs} /$ alumina composite, $(\square) 0.8 \mathrm{wt} \%$ $\mathrm{CNFs} /$ alumina composite, $(\triangle) 0.4 \mathrm{wt} \% \mathrm{CNFs} /$ alumina composite, and (๑) monolithic alumina ceramic.

The relationship between $\mathrm{K}_{\mathrm{IC}}$ and $1 / \mathrm{G}^{2}$ is shown in Fig. 10 . $\mathrm{K}_{\mathrm{IC}}$ was proportional to $1 / \mathrm{G}^{2}$. From this relationship, the following empirical formula could be obtained in the range of our experimentally measured alumina grain size:

$$
\mathrm{K}_{\mathrm{IC}}=\frac{k_{1}}{\mathrm{G}^{2}}+k_{2}
$$

where $k_{1}$ and $k_{2}$ are constants, and may depend on the type (SWCNT, MWCNT, etc.), diameter, length, and surface conditions of the CNTs, as well as the characteristics of the raw alumina powders. This Eq. (2) will hold for the other CNTsceramic composites if the toughening mechanism is the bridging and/or pull-out of CNTs. This equation gives the possibility of fabrication of even stronger toughened composites. That is, the composites with finer grain size will show a higher fracture toughness. Moreover, they will also show a higher strength if they do not have agglomerations of CNFs and insufficiently sintered regions.

The dependence of the fracture toughness of the CNFs/ alumina composites on the alumina grain size can be explained by the bridging and/or pull-out of the CNFs bending at the triple junctions of the alumina grains. Illustrations of the toughening mechanism are shown in Fig. 11. When the alumina grains are smaller, individual CNFs are surrounded by more alumina grains and bend at more triple junctions, as shown in Fig. 11(a). As the number of bendings per CNF increased, the resistance for bridging and/or pull-out of the CNFs adhered closely to the alumina grains became larger, which resulted in an enhancement of the fracture toughness. On the other hand, as the alumina grains grew larger, individual CNFs were surrounded by fewer alumina grains, and the number of bendings per CNF decreased, as shown in Fig. 11(b). Therefore, as the alumina grains became larger, the resistance for bridging and/or pull-out of a $\mathrm{CNF}$ decreased, and consequently, the fracture toughness was not enhanced.

The fracture toughness of the composites was not greatly influenced by the additive amount of CNFs. This can be explained by the resistance for bridging and/or pull-out of the CNFs. The CNFs gathered at the same sites in the grain boundaries through the grain growth of the alumina during sintering, especially in the composites containing larger amounts of CNFs (Fig. 5(b)). The number of CNFs giving rise to the essential effect for bridging and/or pull-out was reduced by gathering at the same sites in the grain boundaries. In addition, the resistance for bridging and/or pull-out of the individual 


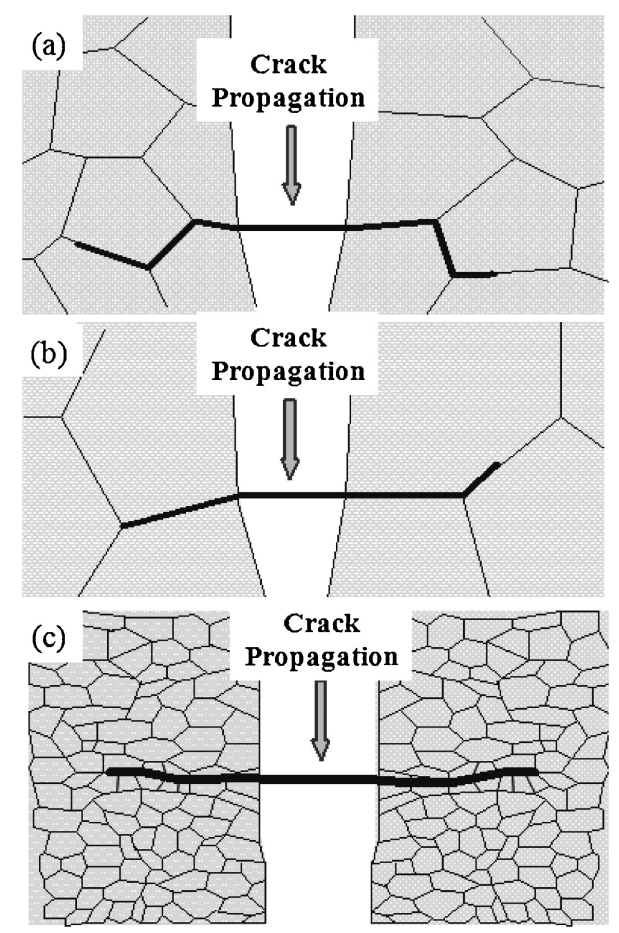

Fig. 11. Schematic illustrations of the pull-out of CNFs in the composites with (a) finer, (b) larger, and (c) much finer alumina grains.

CNFs gathered at the same sites in the grain boundaries might be smaller than that for the bridging and/or pull-out of a single CNF at the grain boundary. Therefore, as the grain growth of alumina progressed, the total resistance for pull-out of CNFs in the composites did not always increase with an increase in the additive amount of CNFs.

A dense matrix consisting of finer alumina grains will cause a much greater resistance for bridging and/or pull-out of CNFs, which will result in a significant improvement in the fracture toughness. However, if the alumina grains are too fine, the CNFs will only be surrounded by many alumina grains and will be regarded as straight or gently curved fibers in the alumina matrix, as shown Fig. 11(c). This condition is quite similar to that of CNFs in the green powder compacts, and thus the resistance for bridging and/or pull-out of CNFs may be very low in this condition. As the densification of the composites and the grain growth of alumina progressed, the CNFs are bent at the grain junctions and the number of bendings increased. However, as the densification and the grain growth progressed further, the number of bendings decreased. This indicates that much finer alumina grains do not cause the large resistance for bridging and/or pullout of CNFs and do not result in significant improvements in the fracture toughness of the composites. That is, the critical alumina grain size that leads to the maximum fracture toughness should exist in the relationship between the fracture toughness and the alumina grain size of the composites shown in Fig. 9 and Fig. 10 .

\section{Conclusions}

High-dispersion-treated carbon nanofibers (CNFs) were used to fabricate uniformly-dispersed CNFs-alumina composites with enhanced mechanical properties. The composites containing high-dispersion-treated CNFs of less than $0.8 \mathrm{wt} \%$ were densified to relative densities of more than $99 \%$ by vacuum sintering and subsequent HIP treatment. The composites containing CNFs of more than $1.6 \mathrm{wt} \%$ could not achieve relative densities of more than $97 \%$ by vacuum sintering and subsequent HIP treatment, but could achieve full density by the plasma activated sintering method (PAS).

The maximum bending strength of the composites (1050 MPa) was approximately the same as that of the monolithic alumina $(1079 \mathrm{MPa})$. If only a small number of CNF agglomerations and only a few insufficiently sintered regions remaining in the composites disappear, the composites will have higher bending strength. The maximum fracture toughness $\left(5.9 \mathrm{MPa} \cdot \mathrm{m}^{0.5}\right)$ represented a $69 \%$ increase compared with that of the monolithic alumina $\left(3.5 \mathrm{MPa} \cdot \mathrm{m}^{0.5}\right)$. This improvement in the fracture toughness resulted from the bridging and/or pull-out of CNFs, and the fracture toughness depended on the alumina grain size of the composites.

The fracture toughness $\left(\mathrm{K}_{\mathrm{IC}}\right)$ increased rapidly with a decrease in alumina grain size $(\mathrm{G})$, and decreased and approached a constant value with an increase in alumina grain size. The relationship was expressed by the following equation: $\mathrm{K}_{\mathrm{IC}}=$ $\left(k_{1} / \mathrm{G}^{2}\right)+k_{2}$ (where $k_{1}$ and $k_{2}$ are constants). A further improvement in the fracture toughness of the composites could be achieved by obtaining dense and fine microstructures with the critical alumina grain size.

Acknowledgements This study was supported by "R\&D for practical application of nanotechnology and advanced components" of the New Energy and Industrial Technology Development Organization (NEDO), Japan, CLUSTER (the second stage) of the Ministry of Education, Culture, Sports, Science and Technology of Japan, and a Grant-in-Aid for Scientific Research from the same Ministry.

\section{References}

1) M. N. Rahaman, "Sintering of Ceramics," CRC Press, Boca Raton (2008) pp. 1-2.

2) C. B. Carter and M. G. Norton, "Ceramic Materials Science and Engineering," Springer, New York (2007) pp. 619-651.

3) A. Krell and J. Klimake, J. Am. Ceram. Soc., 89, 1985-1992 (2006).

4) G. Yamamoto, M. Omori and H. Kimura, Nanotechnology, 19, 315708 (2008).

5) M. Estili and A. Kawasaki, Scr. Mater, 58, 906-909 (2008).

6) M. Estili, A. Kawasaki, H. Sakamoto, Y. Mekuchi, M. Kuno and T. Tsukada, Acta Mater., 56, 4070-4079 (2008).

7) Y. F. Zhu, L. Shi, J. Liang, D. Hui and K. T. Lau, Composites, Part B, 39, 1136-1141 (2008).

8) T. Wei, Z. Fan, G. Luo and F. Wei, Mater. Lett., 62, 641-644 (2008).

9) J. Sun, L. Gao and X. Jin, Ceram. Int., 31, 893-896 (2005).

10) G. D. Zhan and A. K. Mukherjee, Int. J. Appl. Ceram. Technol., 1, 161-171 (2004).

11) J. Sun, M. Iwasa, T. Nakayama, K. Niihara, L. Gao and X. Jin, J. Ceram. Soc. Japan, 112, 403-406 (2004).

12) G. D. Zhan, J. D. Kuntz, J. Wan and A. K. Mukherjee, Nat. Mater., 2, 38-42 (2003).

13) C. Laurent, A. Peigney, O. Dumortier and A. Rousset, J. Eur. Ceram. Soc., 18, 2005-2013 (1998).

14) A. Oberlin, M. Endo and T. Koyama, J. Cryst. Growth, 32, 335-349 (1976).

15) S. Iijima, Nature, 354, 56-58 (1991).

16) T. Xiao, Y. Ren, K. Liao, P. Wu, F. Li and H. M. Cheng, Compos. Sci. Technol., 68, 2937-2942 (2008).

17) A. H. Barber, I. K. Ashiri, S. R. Cohen, R. Tenne and H. D. Wagner, Compos. Sci. Technol., 65, 2380-2384 (2005).

18) C. Wei, K. Cho and D. Srivastava, Phys. Rev. B, 67, 115407 (2003). 
19) C. Q. Ru, Phys. Rev. B, 62, 10405-10408 (2000).

20) J. P. Salvetat and A. J. Kulik, Adv. Mater., 11, 161-165 (1999).

21) J. P. Salvetat, J. M. Bonard, N. H. Thomson, A. J. Kulik, L. Forro, W. Benoit and L. Zuppiroli, Appl. Phys. A: Mater. Sci. Process., 69, 255-260 (1999).

22) E. L. Corral, J. Cesarano, III, A. Shyam, E. L. Curzio, N. Bell, J. Stuecker, N. Perry, M. D. Prima, Z. Munir, J. Garay and E. V. Barrera, J. Am. Ceram. Soc., 91, 3129-3137 (2008).

23) X. Wang, N. P. Padture and H. Tanaka, Nat. Mater., 3, 539-544 (2004).

24) E. T. Thostenson, Z. Ren and T. W. Chou, Compos. Sci. Technol., 61, 1899-1912 (2001).

25) E. Flahaut, A. Peigney, C. Laurent, C. Marliere, F. Chastel and A. Rousset, Acta Mater., 48, 3803-3812 (2000).

26) A. Peigney, C. Laurent, E. Flahaut and A. Rousset, Ceram. Int., 26, 677-683 (2000).

27) R. Z. Ma, J. Wu, B. Q. Wei, J. Liang and D. H. Wu, J. Mater. Sci., 33, 5243-5246 (1998).
28) K. Niihara, R. Morena and D. P. H. Hasselman, "Fracture Mechanics of Ceramics," ed. by R. C. Bradt, A. G. Evans, P. P. Hasselman and F. F. Lange, Plenum, New York (1983) pp. 97105.

29) K. Niihara, R. Morena and D. P. H. Hasselman, J. Mater. Sci. Lett., 1, 13-16 (1982).

30) K. Niihara, R. Morena and D. P. H. Hasselman, J. Am. Ceram. Soc., 65, C-116 (1982).

31) T. Miyoshi, N. Sagawa and T. Sasa, J. Jpn. Soc. Mech. Eng. A, 51, 2489-2497 (1985).

32) P. F. Becher, J. Am. Ceram. Soc., 74, 255-269 (1991).

33) B. Mussler, M. V. Swain and N. Claussen, J. Am. Ceram. Soc., 65, 566-572 (1982).

34) R. W. Rice, S. W. Freiman and P. F. Becher, J. Am. Ceram. Soc., 64, 345-350 (1981).

35) R. W. Rice and S. W. Freiman, J. Am. Ceram. Soc., 64, 350354 (1981). 